\title{
în. talenta SUMEJ \\ The Relationship between Obstructive Sleep Apnea (OSA) and Adherence of Antihypertensive Consumption in Regular Hemodialysis Patient
}

\author{
Lubis Afrilia Rosada ${ }^{1}$, and Muzasti Riri Andri ${ }^{2}$ \\ ${ }^{1,2,}$ Sumatera Utara University College of Medicine, Division of Nephrology-Hypertension, Department of \\ Internal Medicine
}

\begin{abstract}
Based on the Indonesian Renal Registry (IRR) data in 2015, the highest incidence of comorbidities in hemodialysis patients in Indonesia was hypertension (50\%). Obstructive Sleep Apnea (OSA) is one of the causes of secondary hypertension, the characteristics of hypertension in OSA are more resistant to treatment. One of the causes of resistant hypertension is patient non-compliance with the consumption of antihypertensive drugs.
\end{abstract}

Keyword: Adherence to antihypertensive consumption, hemodialysis, obstructive sleep apnea.

\begin{abstract}
Abstrak. Berdasarkan data Indonesian Renal Registry (IRR) pada tahun 2015, insiden komorbiditas tertinggi pada pasien hemodialisis di Indonesia adalah hipertensi $(50 \%)$. Obstructive Sleep Apnea (OSA) adalah salah satu penyebab hipertensi sekunder, karakteristik hipertensi pada OSA lebih resisten terhadap pengobatan. Salah satu penyebab hipertensi resisten adalah ketidakpatuhan pasien dengan konsumsi obat antihipertensi.
\end{abstract}

Kata Kunci: Kepatuhan Terhadap Konsumsi Antihipertensi, Hemodialisis, Apnea Tidur Obstruktif.

Received 3 March 2019| Revised 16 August 2019| Accepted 20 August 2019

\section{Introduction}

Australian and New Zealand Dialysis and Transplant(ANZDATA) states that among 15.4 deaths per 100 dialysis patients / year, $40 \%$ are caused by cardiovascular disease. One of the causes of death due to cardiovascular disease is hypertension.1 Based on IRR data in 2015, the biggest cause of chronic renal disease (CKD) with dialysis was hypertension by $44 \% .^{2}$

Obstructive sleep apnea is one of the causes of secondary hypertension. Approximately $50 \%$ of subjects with OSA are estimated to suffer from hypertension, while 30-40\% of subjects with hypertension are estimated to suffer from OSA. The characteristics of hypertension in OSA are more resistant to treatment. Patients who meet the criteria for resistant hypertension may have

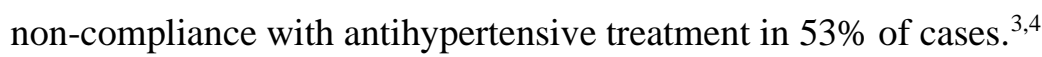

*Corresponding author at: Sumatera Utara University College of Medicine, Medan, Indonesia 
Therefore, the authors are interested in conducting a study of the relationship between obstructive sleep apnea with adherence to the consumption of antihypertensive drugs in hemodialysis patients.

\section{Methodology}

This study was an analytical observational study with a cross-sectional design study. This cross sectional study was performed at Rasyida Kidney Hospital and was to be started after ethical clearance (No. 53 / TGL / KEPK FK USU-RSUP HAM / 2018) was issued by the Ethics Commission FK USU on 89 regular hemodialysis patients.

The questionnaire consisted of three parts,the first part of the questionnaire containing data on respondents' characteristics including age, gender, body mass index, smoking history and duration of hemodialysis. The second part of the questionnaire is STOP-BANG questionnaire, to measure the degree of risk of OSA in patients. The third part of the questionnaire is MMAS (Morisky Medication Adherence Scale) to measure the level of patient compliance with antihypertensive treatment.

\section{Result}

In this study showed that regular HD patients who consumed the most antihypertensive drugs were older adults (40-60 years) as many as (55.1\%) with an average age (49.31 \pm 12.754) years and the most sex was male. as many as (69.7\%). The length of HD that the patient lived on average $(34.96 \pm 36.120)$ months. Body mass index (BMI) of most patients is normal $\left(18.5-25 \mathrm{~kg} / \mathrm{m}^{2}\right)$ as much as $(57.3 \%)$. Based on the history of smoking more HD patients who do not smoke (95.5\%).

The prevalence of HD patients who experience OSA is (39.3\%) with the degree of risk of Obstructive Sleep Apnea (OSA) based on STOP-BANG is low, moderate, high respectively(9\%),(51.7\%), and(39,3\%).

The prevalence of HD patients who adhere to more hypertension drug consumption $(57.3 \%)$ with the degree of compliance with drug consumption based on the Morisky Scale is low, medium, high respectively $(42.7 \%),(30.3 \%)$, and (27\%).

\section{Discussion}

The study sample was 89 regular hemodialysis patients who underwent antihypertensive treatment at the Rasyida Kidney Hospital. In this study it was found that the highest 
$\overline{\text { proportion who underwent HD were older adults (40-60 years) as much as (55.1\%) in line }}$ with IRR data where the highest proportion was $45-64$ years $(61.6 \%){ }^{6}$

The sex that was most obtained was men (69.7\%). In line with the study of Ogna et al $(63.5 \%)$ and Muzasti et al (63.4\%) studies. ${ }^{5,7}$

The length of HD that patients undergo averaged $(34.96 \pm 36,120)$ months a little shorter than the results of a study by Muzasti et al at $(41.4 \pm 24.4)$ months. $^{7}$

The highest proportion of BMI of patients is normal $\left(18.5-25 \mathrm{~kg} / \mathrm{m}^{2}\right)$ at $57.3 \%$ with an average of $24.08 \pm 4.359$ in line with the study of Ogna et al $(26.6 \pm 4.4)$ and Righi et al $(29.9 \pm 5.3) .5,4$

Based on the history of comorbidities of HD patients who took antihypertensive drugs, can be associated with a fairly good lifestyle in terms of the smoking history of the patients who mostly did not smoke as much (95.5\%).

The prevalence of HD patients with OSA (39.3\%) with a risk degree of Obstructive Sleep Apnea (OSA) based on STOP-BANG are low, moderate and high (9\%, 51.7\%, and 39.3\% , respectively). In the study of Ogna et al, HD patients who had a high risk of OSA were (64.4\%) with a score of $\geq 3$ considered as a high risk of OSA. ${ }^{5}$

The prevalence of HD patients who adhere to the consumption of hypertension drugs is (57.3\%) with the degree of drug consumption compliance based on the Morisky Scale are low, medium, high each at $(42.7 \%),(30.3 \%)$, and (27\%). In this study, HD patients who took antihypertensive drugs tend to not adhere to treatment because patients intentionally stopped treatment. In line with the research of Murali et al., As many as (74\%) HD patients discontinued treatment because of 'other reasons' that included patients who did not want to continue treatment. ${ }^{8}$

In this study there was no significant relationship between adherence to drug consumption with OSA risk $(\mathrm{p}=0.679)$ but was significantly affected by age $(\mathrm{p}=0.0001)$, body mass index $(p=0.001)$, and gender $(p=0.03)$. In this study the mean age $(54,857 \pm 11,206)$ was younger than that of the Ogna et al $(65.2 \pm 14.1)$. In the study of Bixler et al., The effect of age on the prevalence of sleep apnea is still unclear, in the study, the prevalence of sleep apnea tends to increase with age, but the clinical significance (severity) of apnea decreases. ${ }^{5,9}$ 
In this study the highest proportion of sex was male, in line with the study of Ogna et al which obtained the highest proportion of men $(\mathrm{p}=0.03)$. According to Soeroso N., the prevalence of OSA in men was more than women due to endocrine factors, but OSA can also occur in women who experience disorders that will increase androgen and consumption of androgen drugs. 5,10

In this study the average BMI of patients was $(25.833 \pm 4.639)$ In line with the study of Sivalingam et al $(p=0.007)$ with the mean BMI $(22.4 \pm 3.7)$. According to Soeroso N., one of the causes of OSA is obesity, especially in the upper part of the body, where fat is accumulated in the neck area which will cause compression of the pharynx..$^{10,11}$

In this study there was no significant relationship between the duration of hemodialysis and OSA risk level $(\mathrm{p}=0.242)$ with the average duration of hemodialysis $(39.485 \pm$ 44.014), HD patients with hemodialysis> 25 months long tended to be more at risk (20 vs $15 \%$ ). However, the Ogna et al. Study found a significant correlation between the duration of hemodialysis and OSA risk levels $(\mathrm{p}=0.026){ }^{5}$

In this study there was no significant association between smoking history and OSA risk level $(\mathrm{p}=0.548)$. In line with the study of Masuda et al $(\mathrm{p}=0.101)$ and Losso et al $(\mathrm{p}=0.78) .{ }^{12,13}$

Table 1 Characteristics of Regular HD patients at Rasyida Kidney Hospital Medan

\begin{tabular}{lc}
\hline \multicolumn{1}{c}{ Variabel } & Mean \pm SD, n (\%) \\
\hline Age (year) & $49.31 \pm 12.754$ \\
Young adults (18-40) & $22(24.7)$ \\
Old adults (40-60) & $49(55.1)$ \\
Elderly (>60) & $18(20.2)$ \\
Gender & \\
Male & $62(69.7)$ \\
Female & $27(30.3)$ \\
Duration of hemodialysis & $34.96 \pm 36.120$ \\
$\leq 25$ months & $45(50.6)$ \\
$>25$ months & $44(49.4)$ \\
Body Mass Index $(\mathrm{BMI})$ & $24.08 \pm 4.359$ \\
Thin $\left(<18,5 \mathrm{~kg} / \mathrm{m}^{2}\right)$ & $6(6.7)$ \\
Normal $\left(18,5-25 \mathrm{~kg} / \mathrm{m}^{2}\right)$ & $51(57.3)$ \\
Fat $\left(25-30 \mathrm{~kg} / \mathrm{m}^{2}\right)$ & $21(23.6)$ \\
Obesity $\left(>30 \mathrm{~kg} / \mathrm{m}^{2}\right)$ & $11(12.4)$
\end{tabular}




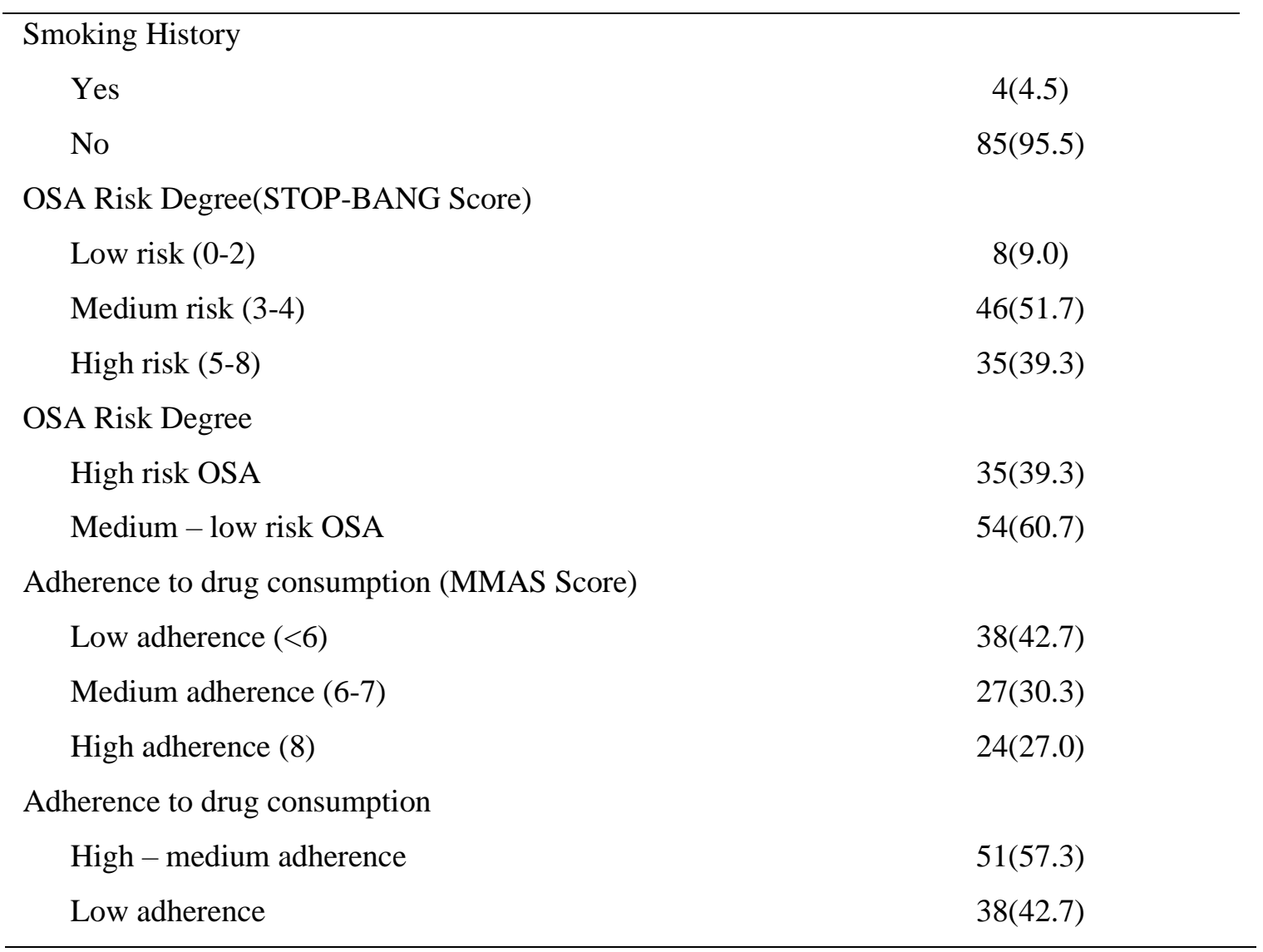

Table 2 characteristics data of HD patients with OSA risk levels

\begin{tabular}{|c|c|c|c|c|c|}
\hline & Total $n=89$ & $\begin{array}{c}\text { High Risk } \\
\text { OSA } \\
\text { Mean } \pm \text { SD, } \\
\text { n (\%) }\end{array}$ & $\begin{array}{c}\text { Medium to } \\
\text { Low Risk OSA } \\
\text { Mean } \pm \text { SD, n } \\
(\%)\end{array}$ & $\mathbf{p}$ & OR(95\% CI) \\
\hline $\begin{array}{l}\text { Adherence to drug } \\
\text { consumption }\end{array}$ & & $\begin{array}{l}5.676 \pm \\
2.211\end{array}$ & $5.454 \pm 2.062$ & 0.679 & 1.200 \\
\hline $\begin{array}{l}\text { High to medium } \\
\text { adherence }(6-8)\end{array}$ & 51 & 21(41.2) & $30(58.8)$ & & $0506 \pm 2.845$ \\
\hline $\begin{array}{l}\text { Low adherence } \\
(<6)\end{array}$ & 38 & $14(36.8)$ & $24(63.2)$ & & \\
\hline Age & & $\begin{array}{c}54.857 \pm \\
11.206\end{array}$ & $45.722 \pm 12.493$ & $0.0001^{\mathrm{a}}$ & 5.000 \\
\hline Adult $(\leq 50)$ & 46 & $10(21.7)$ & $36(78.3)$ & & $1.988 \pm 12.625$ \\
\hline Old $(>50)$ & 43 & $25(58.1)$ & $18(41.9)$ & & \\
\hline Gender & & & & $0.002^{\mathrm{a}}$ & 0,174 \\
\hline Male & 62 & $31(50)$ & $31(50)$ & & $0.54 \pm 0.562$ \\
\hline Female & 27 & $4(14.8)$ & $23(85.2)$ & & \\
\hline $\begin{array}{l}\text { Duration of } \\
\text { hemodialysis }\end{array}$ & & $\begin{array}{c}39.485 \pm \\
44.014\end{array}$ & $32.018 \pm 30.018$ & 0.242 & 1.667 \\
\hline$(\leq 25$ & 45 & $15(33.3)$ & $30(66.7)$ & & $0.707 \pm 3.931$ \\
\hline
\end{tabular}




\begin{tabular}{|c|c|c|c|c|c|}
\hline \multicolumn{6}{|l|}{ bulan) } \\
\hline Old (>25bulan) & 44 & $20(45.5)$ & $24(54.5)$ & & \\
\hline $\begin{array}{l}\text { Body Mass Index } \\
\text { (BMI) }\end{array}$ & & $\begin{array}{c}25.833 \pm \\
4.639\end{array}$ & $22.957 \pm 3.797$ & $0.001^{\mathrm{a}}$ & 4.667 \\
\hline $\begin{array}{r}\text { Normal } \\
\left(\leq 25 \mathrm{~kg} / \mathrm{m}^{2}\right)\end{array}$ & 57 & $15(26.3)$ & $42(73.7)$ & & $1.846 \pm 11.795$ \\
\hline Obesity $\quad(>25$ & 32 & $20(62.5)$ & $12(37.5)$ & & \\
\hline $\left.\mathrm{kg} / \mathrm{m}^{2}\right)$ & & & & & \\
\hline Smoking History & & & & 0.548 & 2.000 \\
\hline Yes & 4 & $1(25.0)$ & $3(75.0)$ & & $0.200 \pm 20.036$ \\
\hline No & 85 & $34(40.0)$ & $51(60.0)$ & & \\
\hline
\end{tabular}

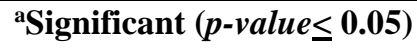

In this study the average BMI of patients was $(25,833 \pm 4,639)$ In line with the study of Sivalingam et al $(\mathrm{p}=0.007)$ with the mean BMI $(22.4 \pm 3.7)$. According to Soeroso N., one of the causes of OSA is obesity, especially in the upper part of the body, where fat is accumulated in the neck area which will cause compression of the pharynx. ${ }^{13,11}$

In this study there was no significant relationship between the duration of hemodialysis and OSA risk level $(\mathrm{p}=0.242)$ with the average duration of hemodialysis $(39.485 \pm 44.014)$, HD patients with hemodialysis > 25 months long tended to be more at risk (20 vs 15\%). However, the Ogna et al. Study found a significant correlation between the duration of hemodialysis and OSA risk levels $(p=0.026){ }^{6}$

In this study there was no significant association between smoking history and OSA risk level ( $p$ $=0.548)$. In line with the study of Masuda et al $(p=0.101)$ and Losso et al $(p=0.78) \cdot{ }^{12,13}$

In this study, based on multivariate analysis there was no correlation between the level of adherence to the consumption of antihypertensive drugs and OSA risk levels in regular HD patients, due to the lack of consistency of HD patients in undergoing treatment. ${ }^{8}$

However, in this study it was found that OSA was significantly affected by age as the dominant risk factor where the risk of regular HD patients with old age (> 50 years) and BMI (> $25 \mathrm{~kg} / \mathrm{m}^{2}$ ) were 6.449 times and 6.130 times the chances of experiencing OSA compared to patients with young age ( $\leq 50$ years ) and lower BMI $\left(\geq 25 \mathrm{~kg} / \mathrm{m}^{2}\right)$, In line with the study of Ogna et al, who obtained an age factor of $>70$ years affected obstructive sleep apnea (OR 1.12; $p=0.07){ }^{6}$ 
Table 3 The final model of multiple logistic regression tests

\begin{tabular}{cccc}
\hline Variabel & OR & p value & 95\% CI \\
\hline Age & 6.449 & 0.001 & $2.246-18.520$ \\
\hline Body Mass Index & 6.130 & 0.001 & $2.105-17.849$ \\
\hline
\end{tabular}

In theory, in line with Eckert et al, that anatomic susceptibility to OSA appears to deteriorate and there is increased fat around the neck as we age. In addition there can also be a loss of lung elasticity as we age, which can affect the upper airway mechanism. ${ }^{14}$

\section{Conclusion}

1. The prevalence of obstructive sleep apnea in HD patients is (39.3\%) with the highest degree of OSA risk is moderate risk (51.7\%).

2. There was no significant relationship between adherence to drug consumption with OSA risk $(\mathrm{p}=0.679)$ but was significantly affected by age $(\mathrm{p}=0.0001)$, body mass index $(\mathrm{p}=0.001)$, and gender $(\mathrm{p}=0.03)$.

3. Based on multivariate analysis, it was found that OSA was influenced by age and BMI as the dominant factor in which the risk of patients aged (>50 years) and BMI (>25 kg / m²) was 6.449 and 6.130 times OSA compared to adult patients ( $\leq 50$ years) and BMI $\left(\leq 25 \mathrm{~kg} / \mathrm{m}^{2}\right)$.

\section{REFERENCES}

[1] Johnson D.W.,Craven A.M., Isbel N.M. 2007, 'Modification of cardiovascular risk in hemodialysis',Hemodialysis International, 11(1), 1-14.

[2] Kementrian Kesehatan RI 2017, Situasi Penyakit Ginjal Kronis accessed 20 April 2018, hal. 5, Available at: : URL: www.pusdatin.kemkes.go.id

[3] Rasyid, H., \& R, S. R. Z. 2016, 'Hubungan Obstructive Sleep Apnea dengan Hipertensi', 43(9), pp. 670-673.

[4] Righi, C. G., Martinez, D., Gonçalves, S. C., Gus, M., Moreira, L. B., Fuchs, S. C., \& Fuchs, F. D. 2017, 'Influence of high risk of obstructive sleep apnea on adherence to antihypertensive treatment in outpatients', The Journal of Clinical Hypertension, 19(5), pp. 534-539.

[5] Indonesian Renal Registry. 2016, '9th Report Of Indonesian Renal Registry', Program Indonesia Renal Registry, pp. 1-46. Accessed 31 November 2018, Available at: https://www.indonesianrenalregistry.org

[6] Ogna, V.F., Ogna, A., Pruijm, M., Bassi, I., Zuercher, E., Halabi, G. et al. 2015, 'Prevalence and Diagnostic Approach to Sleep Apnea in Hemodialysis Patients: A Population Study', BioMed Research International, 2015, pp. 1-9.

[7] Muzasti, R. A. and Lubis, H. R. 2017, 'Is medication adherence associated with total of antihypertensive drugs in chronic hemodialysis patient?', Journal of Hypertension, 35(49).

[8] Murali, K. M., Mullan, J., Chen, J. H. C., Roodenrys, S., \& Lonergan, M. 2017, 'Medication adherence in randomized controlled trials evaluating cardiovascular or mortality outcomes in dialysis patients: A systematic review', BMC Nephrology. BMC Nephrology, 18(1), p. 42.

[9] Bixler, E. O. et al. 1998, 'Effects of Age on Sleep Apnea in Men I . Prevalence and Severity', American Journal of Respiratory and Critical Care Medicine, 157, pp. 144-148.

[10] Soeroso N. 2017, 'Obstructive Sleep Apnoe', Buku Ajar Respirasi, pp. 333-350.

[11] Sivalingam, M. et al. 2012, 'Obstructive sleep apnea in incremental hemodialysis: Determinants, consequences , and impact on survival', Hemodialysis International, pp. 1-10. doi: 10.1111/j.15424758.2012.00729.x. 
[12] Masuda, T., Murata M., Honma S. et al. 2011, 'Sleep-disordered breathing predicts cardiovascular events and mortality in hemodialysis patients', Nephrology Dialysis Transplantation, 26, pp. 22892295. doi: $10.1093 / \mathrm{ndt} / \mathrm{gfq} 756$.

[13]Losso, R. L. M., Minhoto, G. R. and Riella, M. C. 2014, 'Sleep disorders in patients with end-stage renal disease undergoing dialysis: comparison between hemodialysis, continuous ambulatory peritoneal dialysis and automated peritoneal dialysis', International Urology and Nephrology, 47(2), pp. 369-375.

[14] Eckert, D. J. and Malhotra, A. 2005, 'Pathophysiology of Adult Obstructive Sleep Apnea', Proc Am Thorac Soc, 5, pp. 144-153. doi: 10.1513/pats.200707-114MG. 